\title{
Modeling temperature response in bioenergy production: Novel solution to a common
} challenge of anaerobic digestion

Kovalovszki, Adam; Treu, Laura; Ellegaard, Lars; Luo, Gang; Angelidaki, Irini

Published in:

Applied Energy

Link to article, DOI:

10.1016/j.apenergy.2020.114646

Publication date:

2020

Document Version

Peer reviewed version

Link back to DTU Orbit

Citation (APA):

Kovalovszki, A., Treu, L., Ellegaard, L., Luo, G., \& Angelidaki, I. (2020). Modeling temperature response in bioenergy production: Novel solution to a common challenge of anaerobic digestion. Applied Energy, 263, [114646]. https://doi.org/10.1016/j.apenergy.2020.114646

\section{General rights}

Copyright and moral rights for the publications made accessible in the public portal are retained by the authors and/or other copyright owners and it is a condition of accessing publications that users recognise and abide by the legal requirements associated with these rights.

- Users may download and print one copy of any publication from the public portal for the purpose of private study or research.

- You may not further distribute the material or use it for any profit-making activity or commercial gain

- You may freely distribute the URL identifying the publication in the public portal 


\section{Modeling temperature response in bioenergy production: novel solution to a common challenge of anaerobic digestion}

Adam Kovalovszki $^{\mathrm{a}}$, Laura Treu ${ }^{\mathrm{a}, \mathrm{b}, *}$, Lars Ellegaard ${ }^{\mathrm{c}}$, Gang Luo $^{\mathrm{d}}$, Irini Angelidaki ${ }^{\mathrm{a}}$

a Department of Environmental Engineering, Technical University of Denmark, 2800 Kgs. Lyngby, Denmark;

E-mail: adko@env.dtu.dk, iria@env.dtu.dk; latr@env.dtu.dk

${ }^{\mathrm{b}}$ Department of Biology, University of Padua, 35131 Padua, Italy;

E-mail: laura.treu@unipd.it;

${ }^{c}$ Burmeister \& Wain Scandinavian Contractor, Gydevang 35, 3450 Allerød, Denmark;

E-mail: 1se@bwsc.dk;

${ }^{d}$ Department of Environmental Science and Engineering, Fudan University, Handan Road 220, Yangpu District, 200433

Shanghai, China;

E-mail: gangl@fudan.edu.cn

* Corresponding author. Tel.: +390498276306. E-mail address: laura.treu@unipd.it 


\section{Abstract:}

Temperature is one of the most crucial state variables in industrial process control, which is particularly true for the biochemical conversion of biomass, as in anaerobic digestion. However, modeling the effects of temperature changes on anaerobic microbial growth are commonly considered in quasi-steady state, neglecting the timely dynamics of microbial adaptation to such phenomena. To address this inflexibility, the current work presents a new way for temperature effect calculation that improves the simulation efficiency of bioconversion models. The calculation was implemented as a function in a dynamic mathematical model of anaerobic digestion, and was validated via the simulation of experimental data from two laboratory-scale continuous experiments, involving both short- and long-term temperature changes. Model validity was further supported by 16s rRNA gene sequencing data. The bioconversion model extended with the new temperature function showed significant improvements in simulating the most important dependent variables of the digestion process, such as methane production rate and volatile fatty acid concentration during temperature variations. Finally, microbial analysis results shed light on the potential reasons for differences between simulated and experimental results. Overall, the dynamic temperature function was found to be an important addition to the reference model, allowing its user to generate more accurate simulations of digestion processes with changing temperature conditions. Furthermore, it can be seen as a step towards advanced time series forecasting, with potential benefits for integrated process design, process energy optimization and predicting the behavior of full-scale operations affected by ambient temperature conditions.

Keywords: anaerobic digestion; BioModel; dynamic effect; microbial growth; temperature 


\section{Introduction}

Anaerobic digestion (AD) is an industrial fermentation technology that is based on natural processes and builds upon the metabolic activity of primarily anaerobic microorganisms. During AD, relevant bacterial and archaeal species consume, produce and exchange compounds, thus gradually converting soluble and insoluble organic substrates to a number of intermediate products and terminal gases. These gases are mainly methane $\left(\mathrm{CH}_{4}\right)$ and carbon dioxide $\left(\mathrm{CO}_{2}\right)$, but the composition can vary according to the input material and operating conditions applied [1].

Due to its wide range of applications and the variety of products with potential relevance for energy, biotechnology and pharmaceutical industries, AD has long been used for the production of mainly bioenergy and also platform chemicals in small- and large-scale applications worldwide [25]. While an extensive amount of technical knowledge has been generated in the fields of engineering, biochemistry, monitoring and other disciplines, the microbiological aspects of the system are still only partially understood. These started to receive more attention in recent years, due to the emergence of next generation sequencing opportunities [6-8]. In an AD system, environmental conditions may change continuously or definitely, causing stress to the underlying microbial community and potentially affecting process stability and efficiency. For one, microbial sensitivity to changes in temperature outside their preferred range was shown to have a significant influence on their metabolic activity and growth [9]. Multiple studies have shown, for instance, that the community structures differ greatly between anaerobic reactors operated under different temperature conditions $[10,11]$, or can be shifted substantially due to changing operation temperature $[12,13]$. While this might affect production stability [14] and plant operability [15] to varying extents, previous research has pointed out that temperature-induced process optimization can also improve the economy of $\mathrm{AD}$, by lowering operational costs [16] or enabling its combination with other renewable energy technologies [17]. Indeed, temperature seems to be one of the most significant parameters shaping both AD microbial ecology and plant performance. Despite the apparent influence of environmental 
factors and the number of studies already available on the subject, the dynamic effects of temperature changes on $\mathrm{AD}$ process variables are still obscure. This limits the applicability of targeted optimization methods for enhancing microbial bioconversion performance to only steady-state temperature conditions.

Fortunately, computational modeling offers flexible and cost-effective resources to monitor, control and even forecast the behavior of complex and seemingly stochastic biological systems. By virtualizing and simulating fermentation processes, these models can provide insights into numerous operation scenarios at the same time, supporting plant designers ahead of the construction process and saving plant managers both time and resources during operation [18]. With regards to $\mathrm{AD}$, the past decades have seen an ever-increasing level of detail in dynamic process models [19,20], focusing on specific aspects or the whole of the natural process. Two models in particular, the so-called BioModel $([21,22])$ and the Anaerobic Digestion Model 1 (ADM1, [23]), have become widely used for laboratory- and full-scale AD simulation, offering a wide range of functionalities. Using any of these models, nevertheless, requires certain assumptions to be made, including the temperaturedependence of the modeled microbial growth: a trait that directly limits their applicability for evaluating $\mathrm{AD}$ scenarios with substantial or unforeseen temperature variations. Considering the BioModel, for example, the influence of temperature on growth is modeled with a global linear correlation, while in the ADM1, this is done via the application of separate growth coefficients that can only be used under predefined conditions $[23,24]$. In both models, another limitation is the assumption that microbial growth is only affected by temperature at equilibrium (steady-state), without attempting to account for its dynamic effects. Furthermore, as most experiments and fullscale operations are carried out under either mesophilic or thermophilic temperature ranges, they are not intended or expected to incur significant temperature deviations. So far, this has provided no real incentive for the development of transient temperature effect modeling in $\mathrm{AD}$, rendering the topic fairly unexplored and highlighting the need for the study of more accurate temperature models. 
At the same time, as engineering robust or specialized microbial ecosystems through modulating fermentation temperatures is gaining popularity [25], accurate simulations of system behavior during unwanted temperature drops, surges or deliberate shifts start to have a high potential for facilitating operation practice $[15,26,27]$. Not only can these simulations provide guidance to operators on how to react to certain temperature effects, but by doing so, they can also reduce individual workloads and support long-term ambitions for process automation [28]. In the past, many models have been proposed to describe the thermic effect on microbial growth, both in $\mathrm{AD}$ contexts [29] and other interdisciplinary fields, such as food microbiology [30]. Initially, these drew mainly from the classical Arrhenius equation to describe the temperature-dependence of bacterial growth [31], but gradually shifted towards more elaborate explanations of the phenomenon, accounting also for the decrease in growth beyond optimum temperatures [32]. More recently, Huang et al. [33] used an extended version of Arrhenius' work, namely the Eyring-Polányi equation to design their microbial growth-modulating temperature function. Although the new approach proved to generate highly accurate simulation curves for the growth of Escherichia coli, it is not applicable in experiments involving complex microbial communities. Moreover, the model was designed to provide the steady-state growth rates of $E$. coli under different temperature conditions, but not to describe the temporal variations in growth rate due to shifts in temperature. Apparently, the need for a conceptually sound and computationally feasible, dynamic temperature effect model remains unfulfilled in advanced AD modeling.

The present work was therefore prepared to fill this void, aiming to provide a more broadly applicable alternative to the temperature-effect simulation methods currently in use. Accordingly, the objectives of the study were (1) to develop and test a novel dynamic, microbial growth-limiting temperature function in an existing $\mathrm{AD}$ model; (2) to calibrate and validate the implementation, through simulating select experiments with temperature shifts; and finally (3) to collect microbial information about the validation experiments, in support of the simulation results and for providing background evidence for the temperature effect on the AD microbiome. 


\section{Materials and Methods}

\subsection{Development of the new method}

For carrying out the computational simulations of the various experimental scenarios, a multistep dynamic AD model (known as BioModel) was taken as described earlier [21,22,34], using the MATLAB programming environment [35]. In the model, the existing or reference temperature effect calculation $\left(F_{\text {Tref }}\right)$ allowed for the simulation of temperature variation situations, but did not take into account the time requirement of microbial adaptation to changes in temperature. For this reason and to offer a solution for the modeling need stipulated in the introduction section, the $F_{\text {Tref }}$ of the BioModel was replaced by a novel function.

Inspired partly by the mathematical concept of convolution, the new function $\left(F_{\text {Tnew }}\right)$ constitutes the product of a long-term temperature adaptation and a short-term temperature response subfunction, which are to be described further in this subsection. First, however, some initial information must be provided about the rationale behind the development. When talking about growth-modulation in the BioModel, the following terms are to be considered (Eq. 1a and 1b):

$\mu_{i}\left(T_{e}, \Omega\right)=F_{\text {Tref }, i}\left(T_{e}\right) \times F_{\text {Others }, i}(\Omega)$

Eq. 1a

$F_{\text {Others }, i}(\Omega)=\left\{\begin{array}{l}F_{i}(p H) \times \frac{s_{n}}{S_{n}+K_{S_{n}}} \times \frac{K_{I_{m}}}{K_{I_{m}}+S_{m}},\{i \in \mathbb{N} \mid i \in[1 ; 8] \wedge i \neq 4\} \\ F_{i}(p H) \times \frac{S_{L C F A}}{s_{L C F A}+K_{S_{L C F A}}+\frac{S_{L C F A}{ }^{2}}{K_{I_{L C F A}}}} \times \frac{s_{n}}{S_{n}+K_{S_{n}}} \times \frac{K_{I_{m}}}{K_{I_{m}}+S_{m}}, i=4\end{array}\right.$

where $\{i \in \mathbb{N} \mid i \in[1 ; 8]\}$ represents the eight microbial groups contained in the model; $F_{\text {Tref }}$ is the steady-state temperature-dependent maximum growth rate $\left[\right.$ hour $^{-1}$ or day $\left.^{-1}\right]$ assuming the effective or actual temperature $\left(T_{e}\right)$ to be uniformly effective on the whole group; $F_{\text {Others }}$ represents all other growth modulating effects at the given conditions $\Omega$ (substrate and inhibitor concentrations, $\mathrm{pH}$, etc.) that might influence the growth rate of the group; $F(p H)$ is the growth-modulating $\mathrm{pH}$ effect; $S_{n}$ and $K_{S_{n}}$ are the concentration and half-saturation constant of the n-th substrate; $S_{m}$ and $K_{I m}$ are the 
concentration and inhibition constant of the m-th inhibitor; $S_{L C F A}, K_{S_{L C F A}}$ and $K_{I_{L C F A}}$ are the concentration, half-saturation and inhibition constant of long-chain fatty acids; and finally $\mu\left(T_{e}, \Omega\right)$ is the specific growth rate $\left[\right.$ hour $^{-1}$ or day $\left.{ }^{-1}\right]$ of a microbial group. Because $\mu\left(T_{e}, \Omega\right)$ and $F_{\text {Tref }}$ have the same units, $F_{\text {Others }}$ shall be unitless, defined on a scale of 0 to 1 to modulate the relative rate of growth achievable by the group. For simplicity, $F_{\text {Others }}$ and the dependence of $\mu$ on $\Omega$ are excluded from the subsequent mathematical representations of the model growth calculations, although still being considered in the model itself. The reference calculation for the temperature-effect on growth $\left(\mu\left(T_{e}\right)\right)$ [21] is given in Eq. 2 and is illustrated in Figure 1.

$\mu_{i}\left(T_{e}\right)=F_{\text {Tref }, i}\left(T_{e}\right)=\left\{\begin{array}{cc}\mu_{\max , i}-\alpha_{i} \times\left(T_{o p t, i}-T_{e}\right), & T_{e}<T_{o p t, i} \\ \mu_{\max , i} \times \frac{T_{\max , i}-T_{e}}{T_{\max , i}-T_{o p t, i}}, & T_{e}>T_{o p t, i}\end{array}\right.$

In the above equation, $\mu\left(T_{e}\right)$ is the maximum temperature-specific and $\mu_{\max }$ the maximum achievable microbial growth rate $\left[\right.$ hour $^{-1}$ or day $\left.{ }^{-1}\right] ; T_{e}, T_{\text {opt }}$ and $T_{\max }$ are respectively the effective, optimum and maximum growth temperature $\left[{ }^{\circ} \mathrm{C}\right]$; and $\alpha$ is a regression coefficient. As can be seen from the formula, this expression makes the growth rate directly dependent on the effective or actual temperature, and in line with Arrhenius' principle [31] suggests that increasing process temperatures lead to increased growth rates. In addition, the reference temperature function also generates rapid growth drops at temperatures exceeding $T_{\text {opt }}$, assuming the denaturation of intracellular proteins under intolerable thermic conditions. While this correlation provides a conceptually sound estimate for long-term changes in microbial growth due to temperature adaptation, it fails to explain short-term dynamic growth responses to such changes during the adaptation process.

To augment this deficiency and increase the utility of the temperature-effect calculation in the BioModel, the $F_{\text {Tnew }}$ implementation was designed and is presented in Eq. 3a-3e.

$\mu_{i}\left(T_{e}, T_{a, i}\right)=F_{\text {Tnew }, i}\left(T_{e}, T_{a, i}\right)=\boldsymbol{F}_{\boldsymbol{S S}, \boldsymbol{i}}\left(T_{a, i}\right) \times \boldsymbol{F}_{\boldsymbol{D Y N}, \boldsymbol{i}}\left(T_{e}, T_{a, i}\right)$ Eq. $3 a$ 
$\boldsymbol{F}_{\boldsymbol{S S}, i}\left(T_{a, i}\right)=\left\{\begin{aligned} \mu_{\max , i}-\alpha_{i} \times\left(T_{o p t, i}-T_{a, i}\right), & T_{a, i}<T_{o p t, i} \\ \mu_{\max , i} \times \frac{T_{\max , i}-T_{a, i}}{T_{\max , i}-T_{o p t, i}}, & T_{a, i}>T_{o p t, i}\end{aligned}\right.$

$\dot{T}_{a, i}(t)=\frac{T_{e}(t)-T_{a, i}(t)}{\tau_{a, i}}$

$\boldsymbol{F}_{\boldsymbol{D Y N}, i}\left(T_{e}, T_{a, i}\right)=e^{-\frac{\left(T_{e}-T_{a, i}\right)^{2}}{2 \times \sigma_{i}^{2}}}$

$\sigma_{i}=\left(-\frac{s_{h g, i}{ }^{2}}{2 \times \ln 0.5}\right)^{0.5}$

In the new implementation, the reference (steady-state) temperature function $\left(F_{T r e f}\right)$ was divided into a long-term (steady-state) temperature adaptation term $\left(F_{S S}\right)$ and a short-term (dynamic) reaction term $\left(F_{D Y N}\right)$. Besides the maximum growth rate $\left(\mu_{\max }\right)$, the optimum and maximum growth temperatures ( $\left.T_{\text {opt }}, T_{\max }\right)$ and the regression coefficient $(\alpha), F_{S S}$ is also dependent on the temperature to which the microbial group $i$ is adapted $\left(T_{a}\right)$ at any given moment. Using the effective temperature $T_{e}, T_{a}$ is calculated as shown in Eq. $3 \mathrm{c}$, where $\tau_{a}$ is an adaptation time constant that controls the time needed for the microbial group to adapt to a set temperature. Meanwhile, $F_{D Y N}$ describes a bell-shaped curve that has its center in $T_{a}$ and indicates the shock reaction of a given microbial group, when $T_{e}$ changes relative to $T_{a}$. This dynamic element ensures that temperature can not only increase or decrease the model growth rates according to Arrhenius' principle, but also cause immediate growth disturbance responses required to be overcome. In all cases, the extent of growth disturbance due to the deviation between effective and adapted temperature is controlled by the bell-shape parameter $\sigma$, through a constant $\left(s_{h g}\right)$ that defines the change in degrees Celsius resulting in a drop of the growth to half of $F_{S S}$ A visual comparison of $F_{\text {Tref }}$ and $F_{\text {Tnew }}$ is presented in Figure 1 of section 3.1.

Although the original (effective) temperature-dependence was kept in all physicochemical calculations, it was systematically replaced by the new implementation in the calculation of microbial growth. The rationale for this lies in microbial metabolism, as the response of complex biochemical 
systems to temperature changes is fundamentally different from more rapid processes, such as dissociation, ionization or gas-liquid mass transfer. A further distinction was made between individual model microbial groups, based on their potential sensitivity to disturbances. Accordingly, the acetoclastic methanogenic group was separated from the other groups responsible for conversion processes upstream from methane production (e.g. acidogenesis and acetogenesis). This decision was based on the common observation that methanogens are often considered to be the most sensitive, rate limiting group in $\mathrm{AD}$ [36], prone to suffer from suboptimal growth conditions when compared to other microbial groups. To model this clear contrast and simplify the simulation space, the growth rate of the more robust model microbial groups was kept being dependent on $F_{\text {Tref }}$ (assuming nondelayed temperature adaptation), while that of the acetoclastic methanogens was replaced by $F_{\text {Tnew }}$, applying a delay $\tau_{a, 8}>0$ in the temperature adaptation of acetoclastic methanogens.

\subsection{Model validation}

\subsubsection{Study 1 (S1)}

Following the model extension, the accuracy of the model was evaluated by comparing its simulation results to those of the reference model and to two experimental datasets. Data of the first set originated from an earlier experiment [37], where the focus was on monitoring relatively long temperature shifts. The experiment was carried out using three laboratory-scale CSTR reactors, initially operated at the same temperature $\left(37^{\circ} \mathrm{C}\right)$ until day 50 and subsequently changed to 25,45 and $55{ }^{\circ} \mathrm{C}$, for a period of 10 days. Eventually, all reactors were set back to $37^{\circ} \mathrm{C}$ on day 60 , and were kept at this temperature until the end of the experiment. The main reactor operation details of the experiment are summarized in Table 1, while further information can be found in the original article [37].

\subsubsection{Study 2 (S2)}

The second experimental dataset originated from a laboratory-scale AD experiment, specifically designed to simulate microbial growth lag effects and short-term temperature disturbances. The 
experiment was carried out in a lab-scale continuously stirred tank reactor (CSTR), with operation conditions and substrate characteristics described in Table 1. For the analyses of the relevant process variables, such as total solids (TS), volatile solids (VS), total Kjeldahl nitrogen (TKN), total ammonia nitrogen (TAN), volatile fatty acids (VFA), biogas composition and $\mathrm{pH}$, methods were taken as described in [38].

Temperature disturbances were induced at two points of the experiment, after the reactor was initially run at steady-state conditions [39] for one HRT. During the first disturbance, the temperature was decreased from $53{ }^{\circ} \mathrm{C}$ to $40{ }^{\circ} \mathrm{C}$ on day 77 , together with a decrease in the organic loading rate (OLR) from 2.5 to $2 \mathrm{~g} \mathrm{~L}^{-1} \mathrm{~d}^{-1}$ through the removal of the co-substrate. After one day, the temperature was reset to $53{ }^{\circ} \mathrm{C}$ and time was given for the reactor to reach steady-state production again, before the second disturbance. After almost two HRTs, the temperature was increased to $60{ }^{\circ} \mathrm{C}$ on day 105 for one day. After this disturbance, the reactor was again set back to the initial temperature of $53{ }^{\circ} \mathrm{C}$. 
Table 1: Reactor operation and feed composition data for the two validation studies

\begin{tabular}{|c|c|c|c|c|c|}
\hline & & $\begin{array}{c}\text { Study } 1 \\
\text { (S1) }\end{array}$ & & y 2 & \\
\hline \multirow{4}{*}{$\begin{array}{l}\text { Operation } \\
\text { conditions }\end{array}$} & $\begin{array}{c}\text { Working } \\
\text { volume (V) }\end{array}$ & 0.7 & \multicolumn{2}{|c|}{1.8} & {$[\mathrm{~L}]$} \\
\hline & HRT & 14 & \multicolumn{2}{|c|}{15} & [days] \\
\hline & $\mathrm{T}_{\text {operation }}$ & 37 & \multicolumn{2}{|c|}{53} & {$\left[{ }^{\circ} \mathrm{C}\right]$} \\
\hline & $\begin{array}{l}\mathrm{T}_{\text {disturbance }} \\
\text { (period) }\end{array}$ & $\begin{array}{c}25 / 45 / 55 \\
(50-60)\end{array}$ & $\begin{array}{c}40 \\
(77-78)\end{array}$ & $\begin{array}{c}60 \\
(105-106)\end{array}$ & $\begin{array}{l}{\left[{ }^{\circ} \mathrm{C}\right]} \\
{[\text { day }]}\end{array}$ \\
\hline \multirow{5}{*}{$\begin{array}{c}\text { Feed } \\
\text { loading } \\
\text { rate }\end{array}$} & & manure & manure & $\begin{array}{l}\text { meadow } \\
\text { grass }\end{array}$ & \\
\hline & OLR & 1.8 & 2 & 0.5 & {$\left[\mathrm{~g} \mathrm{~L}^{-1} \mathrm{~d}^{-1}\right]$} \\
\hline & Period & $0-112$ & \multicolumn{2}{|c|}{$60-77$} & [days] \\
\hline & OLR & & 2 & 0 & {$\left[\mathrm{~g} \mathrm{~L}^{-1} \mathrm{~d}^{-1}\right]$} \\
\hline & Period & & \multicolumn{2}{|c|}{$77-136$} & [days] \\
\hline \multirow{8}{*}{$\begin{array}{c}\text { Feed } \\
\text { composition }\end{array}$} & $\mathrm{TS}$ & $36.60^{\mathrm{a}}$ & 38.80 & $926.48^{\mathbf{b}}$ & \multirow{8}{*}[\mathrm{g}\mathrm{L}^{-1}]{} \\
\hline & VS & $25.20^{\mathrm{a}}$ & 30.00 & $863.97^{\mathbf{b}}$ & \\
\hline & TKN & $2.20^{\mathrm{a}}$ & 2.46 & $17.92^{\mathrm{c}}$ & \\
\hline & TAN & n.a. & 1.38 & n.a. & \\
\hline & HPR & n.a. & 1.02 & n.a. & \\
\hline & HBUT & n.a. & 0.64 & n.a. & \\
\hline & HVAL & n.a. & 0.27 & n.a. & \\
\hline & $\mathrm{HAC}$ & n.a. & 3.85 & n.a. & \\
\hline
\end{tabular}

a Values from [37]

b Values from [39]

c Calculated from [34]

n.a. Data was not available (assumed values used for simulation) 


\subsubsection{Parameter selection}

Table 2 provides a summary of the parameter values used in the simulation of the experimental datasets. Simulations were run with the BioModel and for comparability purposes, universal $\tau_{a}$ and Shg values were used throughout all cases.

Table 2: Summary of the parameter values used to simulate the temperature effect on microbial growth in S1 and S2

\begin{tabular}{|c|c|c|c|c|c|c|c|}
\hline \multirow[b]{2}{*}{$i$} & \multirow{2}{*}{$\begin{array}{l}\text { Group } \\
\text { Name }\end{array}$} & \multicolumn{6}{|c|}{ BioModel parameter used } \\
\hline & & $\begin{array}{l}\mu_{\max } \\
{\left[\mathrm{h}^{-1}\right]}\end{array}$ & $\begin{array}{c}\alpha \\
{\left[{ }^{\circ} \mathrm{C}^{-1} \mathrm{~h}^{-1}\right]}\end{array}$ & $\begin{array}{c}T_{o p t} \\
{\left[{ }^{\circ} \mathrm{C}\right]}\end{array}$ & $\begin{array}{l}T_{\max } \\
{\left[{ }^{\circ} \mathrm{C}\right]}\end{array}$ & $\begin{array}{r}\tau_{a} \\
{[\mathrm{~h}]}\end{array}$ & $\begin{array}{l}\text { Shg } \\
{\left[{ }^{\circ} \mathrm{C}\right]}\end{array}$ \\
\hline 1 & Carbohydrate degraders & 0.212 & $3.9 \times 10^{-3}$ & 55 & 65 & & \\
\hline 2 & Amino acid degraders & 0.266 & $4.9 \times 10^{-3}$ & 55 & 65 & & \\
\hline 3 & Lipid degraders & 0.022 & $4.1 \times 10^{-4}$ & 55 & 65 & & \\
\hline 4 & Long-chain fatty acid degraders & 0.023 & $4.2 \times 10^{-4}$ & 55 & 65 & n. $d$. & n. $d$. \\
\hline 5 & Propionic acid degraders & 0.020 & $3.7 \times 10^{-4}$ & 53 & 65 & & \\
\hline 6 & Butyric acid degraders & 0.028 & $5.2 \times 10^{-4}$ & 60 & 70 & & \\
\hline 7 & Valeric acid degraders & 0.029 & $5.3 \times 10^{-4}$ & 60 & 70 & & \\
\hline 8 & Acetic acid degraders/Methanogens & 0.026 & $4.7 \times 10^{-4}$ & 55 & 65 & 240 & 3 \\
\hline
\end{tabular}

n. $d .:$ not defined

\subsection{Microbial analyses}

With regards to S1, raw sequencing data of microbial samples were taken from the open-source metagenomics RAST server (mg-RAST, [40]) and were reanalyzed according to the computational methods further described for S2. This was necessary, in order to achieve results comparable with the analysis of S2.

Considering S2, samples for microbial analysis were collected from the CSTR in triplicates (5 ml each) during the experimental period, at five time points (Figure 4, magenta asterisks). For genomic DNA extraction, the PowerSoil ${ }^{\circledR}$ DNA Isolation Kit (MO BIO laboratories Inc., Carlsbad, CA, USA) 
was used following the manufacturer's instructions with minor modifications, and the quantification of DNA yield was as previously described [41].Amplicon sequences of 16S rRNA gene V4 hypervariable region were obtained using universal (bacterial and archaeal) PCR primers, i.e. 515F and 806R [42]. Illumina MiSeq platform was selected for amplicon sequencing at the Ramaciotti Centre for Genomics (Sydney, Australia). All Illumina reads obtained from sequencing were deposited in the public database of the National Center for Biotechnology Information (NCBI) under the BioProject PRJNA565735, with individual sample accession numbers SAMN12766834, SAMN12766835, SAMN12766836, SAMN12766837, SAMN12766838 reported in the sequence read archive (SRA) database. CLC Workbench software (V.8.0.2) with Microbial genomics module plug in (QIAGEN Bioinformatics, Germany) was used for standard data processing as previously described [41]. In particular raw sequencing quality filtering, operative taxonomical units (OTUs) clustering and taxonomic assignment using Greengenes v13_8 database as reference were applied. The reads obtained per sample were between 140 and 280 thousand, providing enough coverage for obtaining a reliable overview of the main taxa present in the $\mathrm{AD}$ microbiome [43]. Consensus sequences of the dominant OTUs ( $>0.5 \%$ of relative abundance) were confirmed using the BLAST software and the 16S ribosomal RNA database (Bacteria and Archaea) of NCBI. Specific threshold for taxonomic assignment were adopted from previous work based on similarity values [44]. Finally, the MultiExperiment Viewer software (MeV 4.9.0) with complete linkage Pearson correlation was used for heat maps and hierarchical clustering analysis [45].

\subsection{Statistical and visualization methods}

In conjunction with the microbial analyses, a 2-sided Welch's t-test was performed. To identify significant abundance differences of the microbial community between samples, the Statistical Analysis of Metagenomics Profiles (STAMP) software was used [46] and p-value thresholds were set to 0.05 . The R software was used for correlation analyses. Canonical correspondence analysis 
(CCA) was performed using the VEGAN package v2.4-4, based on Pearson and Non-metric Multidimensional Scaling (NMDS) as previously described [47].

With regards to simulation regression analyses, the root mean squared errors (RMSE) between experimental and simulated data points were calculated. RMSE were chosen to provide quantitative information on the goodness-of-fit achieved with the simulations, the calculation of which is presented in Eq. 4:

$R M S E=\sqrt{\frac{\sum_{i=1}^{n}\left(y_{i}-f\left(x_{i}\right)\right)^{2}}{D F}}$

where $n$ is the number of experimental data points, $D F$ is the degrees of freedom $(n-2), y_{i}$ are measured and $f\left(x_{i}\right)$ are simulated values. Using this metric, the percentage-wise improvements in simulation errors were also calculated. For each case study and variable $\left(\mathrm{CH}_{4}\right.$ or VFA), a scale was defined by taking the respective RMSE value of the simulation with $F_{\text {Tref }}$ as $0 \%$ and the perfect fit as $100 \%$, on which scale the RMSE value of the simulation with $F_{\text {Tnew }}$ was placed.

Ultimately, probability plots were drawn to provide a combined normality test for the simulation results [48]. Due to the expectation of having normally distributed measurement noise in the experimental data, this method was selected to evaluate whether the distribution of experimental data points around the simulation curves was normal (signifying good fits), or any of the models was under- or overfitting the data. For plotting the results in the different figures, the OriginPro software [49] was used.

\section{Results}

\subsection{Comparison of temperature functions}

Using the model descriptions given in section 2.1, the behavior of $F_{\text {Tref }}$ and $F_{\text {Tnew }}$ is visualized on the $T_{e}$ range of 0 to $65^{\circ} \mathrm{C}$ and shown in Figure 1. Given the reference model (Figure 1a) assumes quasi-stationary temperature conditions (i.e. instant adaptation to temperature changes), its estimates for the maximum specific growth rates $\mu\left(T_{e}\right)$ at different temperatures only depend on the 
temperatures themselves (colored dots). To offer an example, when changing the operation from mesophilic $\left(37^{\circ} \mathrm{C}\right)$ to thermophilic $\left(55^{\circ} \mathrm{C}\right)$ temperature, the reference model would suggest an immediate increase in microbial growth rate. This is in contrast to practical experience [15], which indicates that such a change would lead to a short-term negative disturbance in microbial activity, before the newly adapted community could develop and reach higher growth rates in line with thermodynamic expectations.

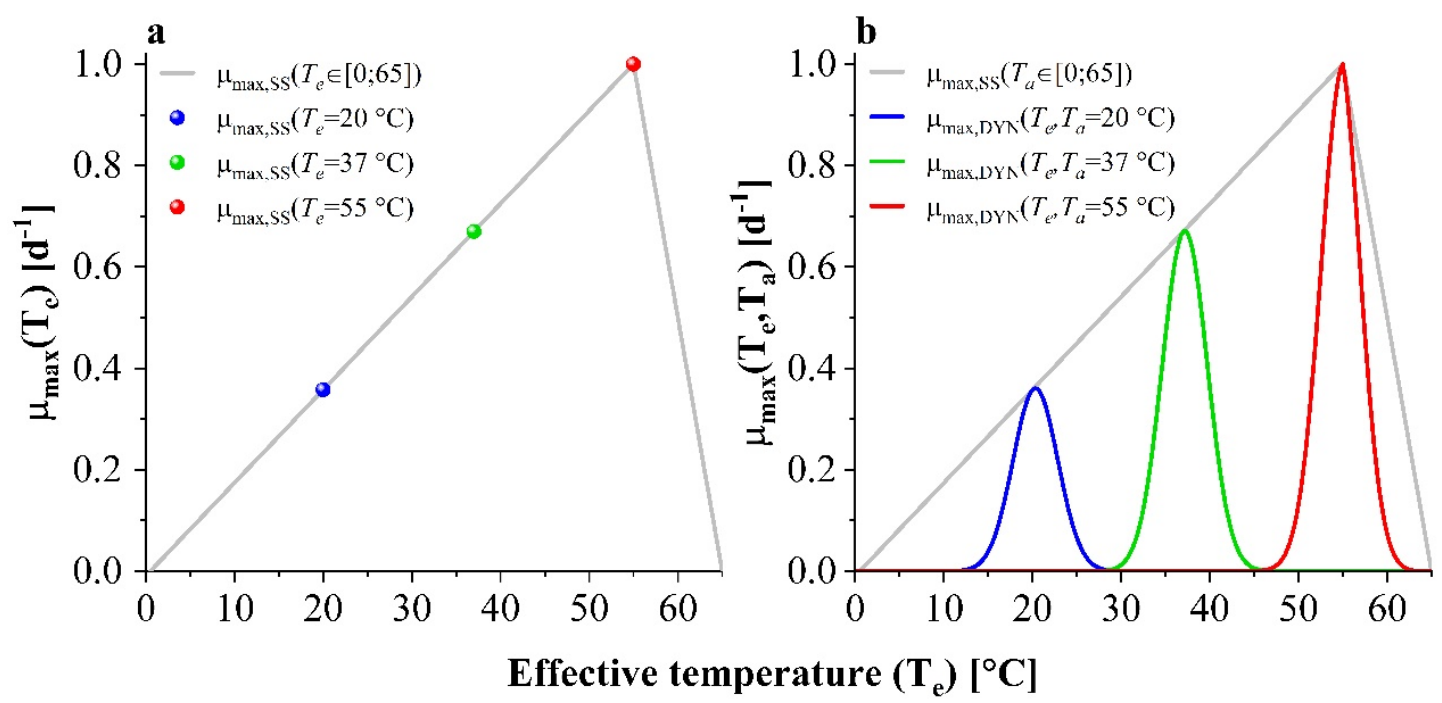

Figure 1: Different temperature function curves generated with (a) $F_{\text {Tref }}$ and (b) $F_{\text {Tnew }}$, showing the calculated growth-modulating effects as a function of the effective $\left(T_{e}\right)$ and adapted $\left(T_{a}\right)$ temperatures. The parameters in (a) were: $\mu_{\max }=1, \alpha=1.8 \times 10^{-2}, T_{\text {opt }}=55^{\circ} \mathrm{C}, T_{\max }=65^{\circ} \mathrm{C}$; the additional parameter in (b) was: $s_{h g}=3{ }^{\circ} \mathrm{C}$.

In fact, Figure $1 \mathrm{~b}$ shows exactly this behavior. Here, the previously direct growth correlations with effective temperatures $\left(\mu_{S S}\left(T_{e}\right)\right)$ are amended by dynamically correlated growth curves $\left(\mu_{D Y N}\left(T_{e}, T_{a}\right)\right)$, which depend both on the effective temperatures $T_{e}$ and the maximum growth rates at the temperatures to which the microbial communities are adapted $\left(\mu_{S S}\left(T_{a}\right)\right)$. Unlike before, $T_{e}$ is now used indirectly to measure its difference from $T_{a}$, and determine the immediate growth effect (colored curves). With time, $T_{a}$ gradually gets closer to $T_{e}$, and the simulated growth recovers to steady-state level, as the difference between the two temperatures diminishes. 
Figure 2 offers a fictive example case, with the purpose of further clarifying the differences between the simulation approaches and focusing only on the impact of temperature on growth rates. In this example, the operation temperature was $37^{\circ} \mathrm{C}$ upon initiation, then on day 10 it was changed to $45^{\circ} \mathrm{C}$ and finally from day 20 to 60 was set to $37^{\circ} \mathrm{C}$ again. Optimum growth rate is assumed to be 1.0 per day at $55^{\circ} \mathrm{C}$.
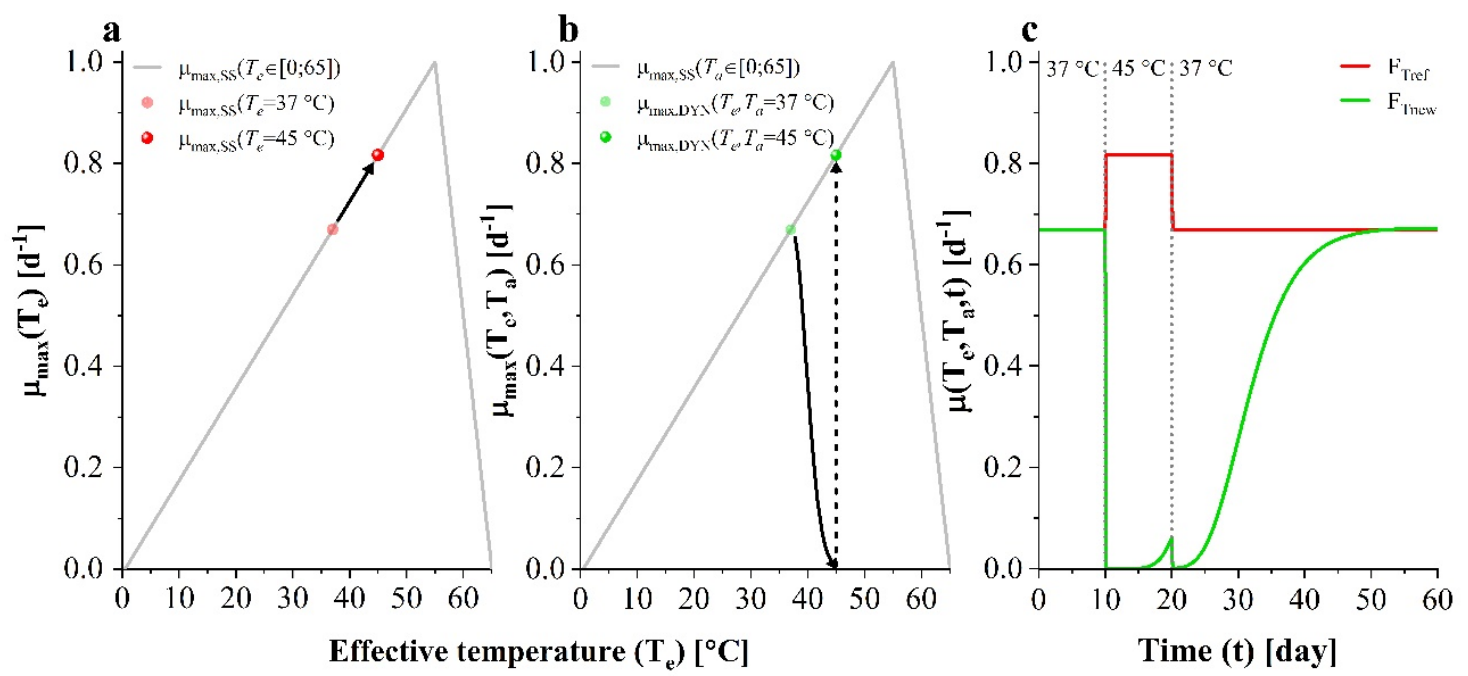

Figure 2: Example temperature function curves generated with (a) $F_{\text {Tref }}$ and (b) $F_{\text {Tnew }}$, showing the calculated growth-modulating effects as a function of the temperature change from 37 to $45^{\circ} \mathrm{C}$ and back. Subplot (c) shows the specific growth rates in time, reflecting the conditions visualized in (a) and (b). The parameters in (a) and (b) were as stated in Figure 1. For plotting the simulation with $F_{\text {Tnew }}$ in (c), the adaptation time constant $\tau_{\mathrm{a}}$ was chosen as 10 days (240 hours) and shg was $3{ }^{\circ} \mathrm{C}$.

The temperature increase on day 10 (Figure $2 \mathrm{c}$ ) results in a concomitant increase of $\mu_{\max }\left(T_{e}\right)$, when using $F_{\text {Tref }}$ for simulation (Figure $2 \mathrm{a}$ ); on the other hand, $F_{\text {Tnew }}$ simulates an initial drop in $\mu_{\max }\left(T_{e}, T_{a}\right)$ due to the change in $T_{e}$, that is followed by a gradual recovery as $T_{a}$ shifts from 37 to $45{ }^{\circ} \mathrm{C}$ (Figure 2b). The timely effects of these two approaches are compared in Figure 2c. While the curve generated with $F_{\text {Tref }}$ indicates an immediate increase in growth $\left(\mu\left(T_{e}, T_{a}, t\right)\right)$ upon temperature change, the extended model simulation (green curve) appears more realistic. In this case, the temperature change causes an initial drop and nearly complete cessation of microbial growth, which starts recovering 
after a few days as a consequence of the shift in $T_{a}$. However, on day 20 the temperature is reset from $45{ }^{\circ} \mathrm{C}$ to $37{ }^{\circ} \mathrm{C}$, causing another disturbance in the growth of the partially adapted microorganisms and leading to another drop. Due to the adaptation being far from complete, this second drop remains moderate. Naturally, these results are also influenced by the selected parameter values for $\tau_{\mathrm{a}}$ and shg, therefore the exemplary role of this case should be re-iterated. Regardless, the new model was demonstrated to capture both the long- and short-term microbial growth response to temperature changes, and introduce life-like dynamicity to a calculation that is commonly approximated by equilibrium.

\subsection{Validation results}

\subsubsection{Medium-term temperature changes}

\subsubsection{Mesophilic temperature decrease $\left(\mathrm{R}_{\mathrm{A}}\right)$}

Simulations of the case study S1 (Table 1) were run both with the reference BioModel [28] and with the extended version; the results are shown in comparison to experimental values in Figure 3.

Starting with Reactor $A\left(R_{A}\right)$ and given the lack of dynamic temperature response in the reference BioModel, it appears as no surprise that the result of the simulation with this version of the model was almost not affected by the temperature drop after day 50 of the experiment (Figure 3). Although a slight decrease in $\mathrm{CH}_{4}$ production could be seen for the duration of the temperature shift, this was a direct consequence of the thermodynamically lower growth rate suggested by the reference model. Meanwhile, the simulation with the $F_{\text {Tnew }}$ implementation was much more accurate: especially in terms of trends, but the magnitudes were also comparable. The combined effect of the long-term growth decrease and the immediate shock led to a significant reduction in methanogenic activity, causing an elongated drop in $\mathrm{CH}_{4}$ production and an equally long VFA accumulation period. Indeed, microbial analysis (Figure 4, S1) showed that during the temperature shift to $25{ }^{\circ} \mathrm{C}$ the community had undergone substantial changes. The result was a drop in the abundances of some of the main methanogenic species, namely Methanoculleus palmolei OTU056 and Methanosarcina soligelidi 
OTU058 (Figure 4, S1b). Similarly, two of the most abundant bacterial OTUs (i.e. Pseudomonas caeni OTU02 and Herbinix luporum OTU04) significantly decreased in abundance upon temperature drop (Figure 4, S1a). These carbohydrate-degrading bacteria are probably related to the hydrolytic step of $\mathrm{AD}$, and are responsible for VFA production. Their dominance was eventually regained (partially or completely), following the temperature reset (see Figure 4, S1 and the Supplementary Material A2).
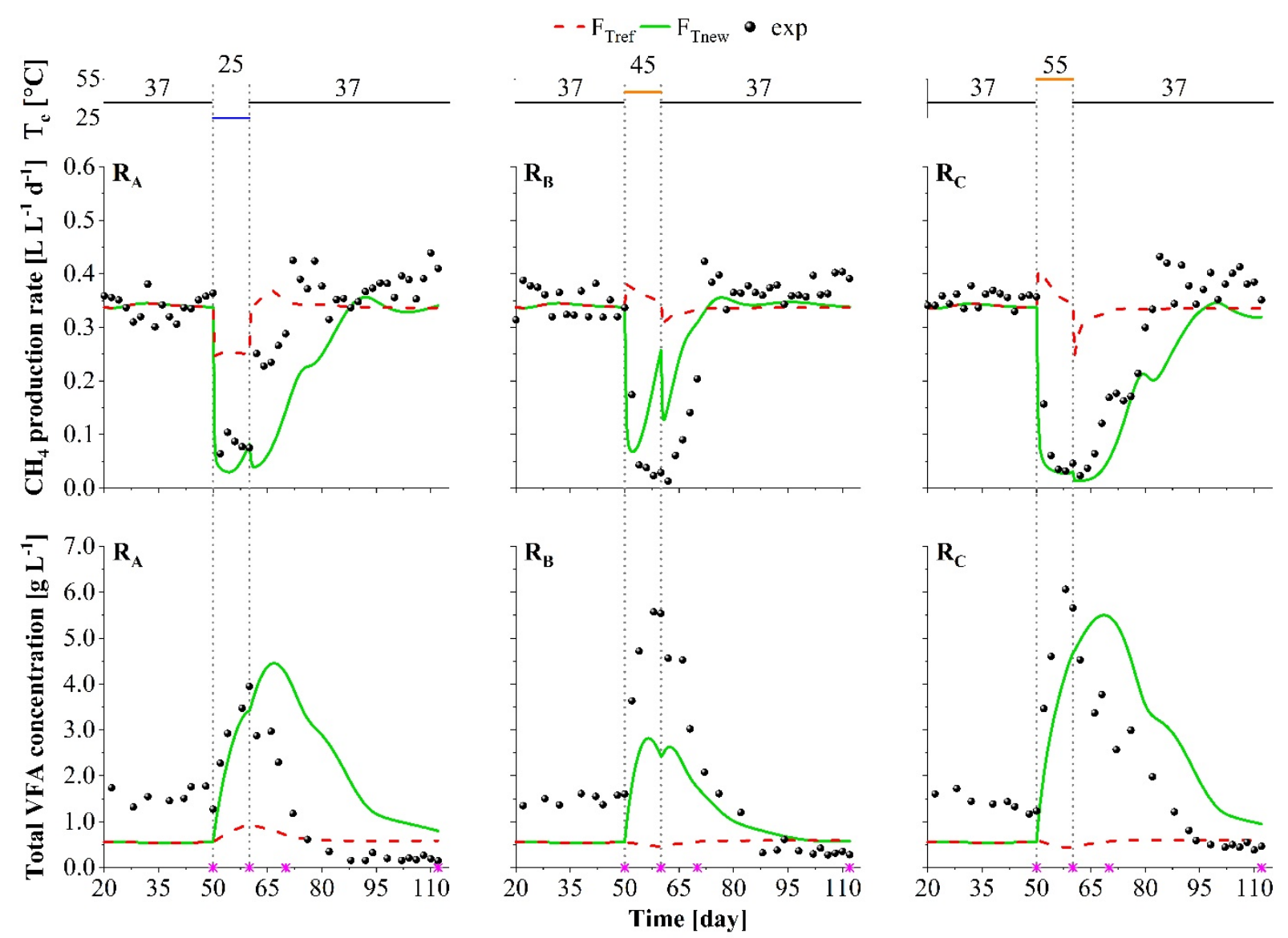

Figure 3: $\mathrm{CH}_{4}$ production rates and total VFA concentration values of $\mathrm{R}_{\mathrm{A}}, \mathrm{R}_{\mathrm{B}}$ and $\mathrm{R}_{\mathrm{C}}$, taken from the experiment (black dots), and simulated with the reference and newly extended BioModel (red dashed and green solid lines, respectively). Dotted vertical lines and the scales at the top of the graph indicate the changes in temperature. Magenta asterisks mark reactor sampling days for microbial community analysis. 

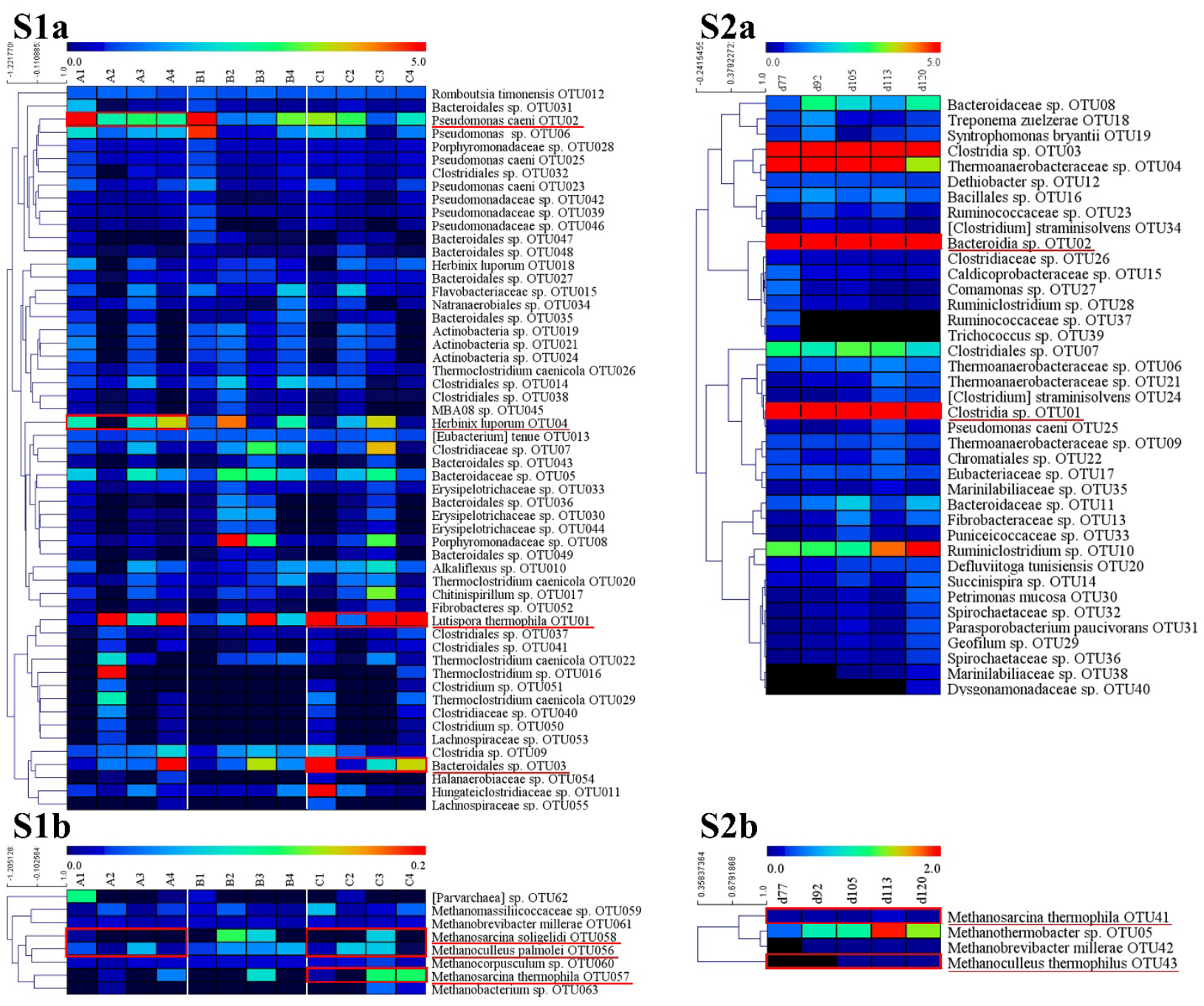

Figure 4: Pearson clustering of the microbial abundances in $(a)$ the four samples taken from Reactor A, B and C of S1 on day 50, 60, 70 and 112 of the experiment (reanalyzed after [37]), and (b) the five reactor samples taken from S2 on day 77, 92, 105, 113 and 120. Red rectangles and underlining mark bacterial and archaeal taxonomic subgroups discussed in more detail.

\subsubsection{Mesophilic temperature increase $\left(R_{B}\right)$}

In Figure 3, the measured and simulated data of Reactor $B\left(R_{B}\right)$ can also be seen, where the temperature was increased from 37 to $45^{\circ} \mathrm{C}$ between days 50 and 60 . Due to the static response of the reference model, the activity of the model methanogens was shown to increase, at a time when both the measured and improved simulation data indicated great distress. On the other hand, neither of the models could accurately explain the high VFA concentrations measured, although the $F_{\text {Tnew }}$ 
implementation was much closer. One reason for this could be that the BioModel assumes the existence of eight interconnected model microbial groups, of which only one (the acetoclastic methanogenic group) is responsible for the conversion of VFA (acetate) to $\mathrm{CH}_{4}$. Despite the low accuracy of VFA simulations, statistical results still showed significant improvements when using the $F_{\text {Tnew }}$ implementation (see in the Supplementary Material A1), similar to those seen for $\mathrm{R}_{\mathrm{A}}$.

\subsubsection{Mesophilic to thermophilic temperature $\left(\mathrm{R}_{\mathrm{C}}\right)$}

The last and probably most intriguing simulation scenario was that of $\mathrm{R}_{\mathrm{C}}$ from case study $\mathrm{S} 1$ (Figure 3). Here, the temperature of the reactor was increased from 37 to as much as $55^{\circ} \mathrm{C}$, and was kept at this high level between days 50 and 60 . Among the three reactors of $\mathrm{S} 1$, the length of the recovery period after the temperature disturbance was the longest in $\mathrm{R}_{\mathrm{C}}$, affecting both the $\mathrm{CH}_{4}$ production and VFA concentration significantly. However, while the reference model simulation produced an outcome similar to that seen for $\mathrm{R}_{\mathrm{B}}$, results from the new model were much more accurate. The recovery period was particularly well captured, both in terms of $\mathrm{CH}_{4}$ production and VFA concentration. Considering the real methanogenic community (Figure 4, S1b), this long adaptation was characterized by an initial increase in the abundance of Methanoculleus palmolei OTU056, which was succeeded by the more versatile [50] Methanosarcina soligelidi OTU058 and the thermophilic Methanosarcina thermophila OTU057 as the operation temperature was reset to 37 ${ }^{\circ} \mathrm{C}$. Yet as shifts in the microbial community cannot be captured with the BioModel, the higher quality of simulation fits in this case was probably due to the suitability of the selected simulation parameters. With regards to the bacterial population, Lutispora thermophila OTU01 and Bacteroidales sp. OTU03 were the dominant microbes in the beginning (responsible for the first steps of AD) and were greatly affected from the temperature shock, only to recover their abundance in the long term (Figure 4, S1a and Supplementary Material A2). The simulation statistics for $\mathrm{R}_{\mathrm{C}}$ were similar to those of $\mathrm{R}_{\mathrm{B}}$, and as expected from the visual results, indicated the advantage of the extended model over the reference. 


\subsubsection{Short-term temperature changes}

The simulation process of the second validation study (S2) (Table 1) resembled the process of S1 (Figure 5).

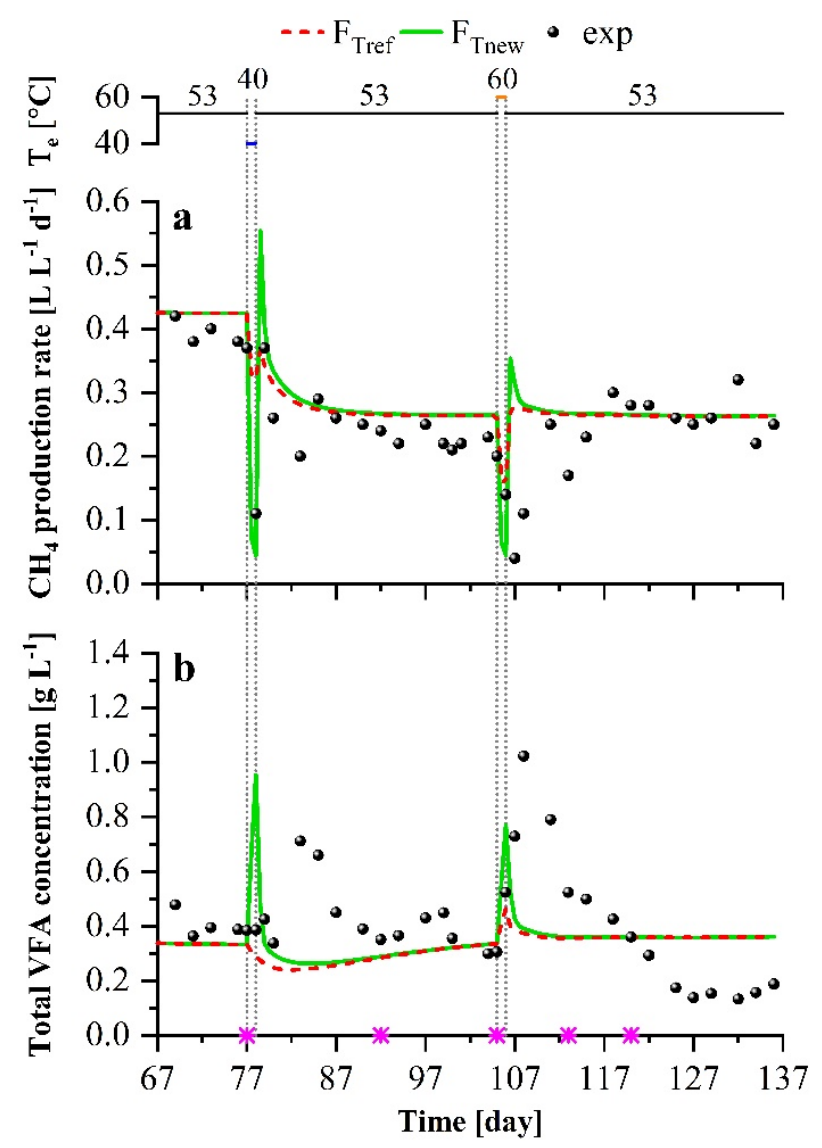

Figure 5: $\mathrm{CH}_{4}$ production rates $(a)$ and total VFA concentration values $(b)$ of $\mathrm{S} 2$, taken from the experiment (black dots), and simulated with the reference and newly extended BioModel (red and green lines, respectively). Dotted vertical lines and the scale at the top of the graph indicate the changes in temperature. Magenta asterisks mark reactor sampling days for microbial community analyses.

Clearly, the reference simulation (red lines) yielded relatively unresponsive curves for both $\mathrm{CH}_{4}$ production rates and total VFA concentrations, while the visible long-term decrease in the simulated $\mathrm{CH}_{4}$ production after day 77 was due to the decrease of OLR from 2.5 to $2 \mathrm{~g} \mathrm{~L}^{-1} \mathrm{~d}^{-1}$. On the other hand, the new model simulation (green lines) captured both experimental trends significantly better. 
In terms of $\mathrm{CH}_{4}$ production rates, this meant that even the lowest measured values could be simulated, although the recovery trends appeared to be faster than those seen experimentally. This also led to the rapid utilization of the accumulated VFA, causing artificial $\mathrm{CH}_{4}$ overshoots directly after the temperature was set back to $53{ }^{\circ} \mathrm{C}$. Concerning total VFA concentrations, the accumulation phenomenon was predicted after the low and high temperature shocks alike, with simulated values reaching peak levels comparable to those measured. Although the novel model remained unable to provide an explanation for the long VFA accumulation periods after the shock events, these might have been due to other dynamic effects (such as slower recovery than shock reaction) that the model does not account for. Furthermore, another reason could have been that the model structure leads to inversely proportional changes in VFA concentration and $\mathrm{CH}_{4}$ production simulations, as it was indicated previously. In other words, any dynamic changes in the concentration of these methanogens would influence the balance between the simulated VFA concentration and $\mathrm{CH}_{4}$ production.

Statistical analyses of the extended model simulations indicated minor improvements in RMSE values compared to the reference values, while the normality of the results remained similar to the reference trends (details shown in the Supplementary Material A1). Considering the microbial analysis results, these provided qualitative and quantitative support for the simulations. In terms of community composition (Figure 4, S2), the stability of the species present throughout the 5 sampling points showed that short-term temperature disturbances did not alter the community structure significantly, in line with earlier findings [51]. In fact, the main bacterial taxa (e.g. Clostridia $s p$. OTU01 and Bacteroidia sp. OTU02) were decreasing in abundance by less than 1.5 -fold (Supplementary Material A2). However, when evaluating the changes in the abundances of specific taxa, the trends in VFA concentration seem to be justified. More specifically, the low abundances of the main archaeal groups (the acetotrophic methanogen Methanosarcina thermophila OTU41 and the hydrogenotrophic methanogen Methanoculleus thermophilus OTU43) after the temperature disturbances, together with their eventual 2-9 fold significant increase (see Supplementary Material 
A2) could have been the respective reasons behind prolonged VFA accumulation and its ultimate decrease. Such community-level shifts, however, cannot be reproduced by using a single model microbial group for acetic acid conversion into methane.

\section{Discussion}

\subsection{Evaluation of results}

Using case studies S1 and S2, it was shown that the extended temperature function led to significantly improved model simulations. This result was well in line with the aim of the study, which was to implement and validate a dynamic temperature function in the microbial growth calculation of the BioModel. Nevertheless, some aspects of the simulations would still benefit from additional model development. For example, simulations of the total VFA concentration in the two studies indicated that the steady-state experimental concentrations could not always be matched accurately, in particular between days 20 and 50 of the S1 subcases, or between days 122 and 137 of S2. However, this deviation can most probably be attributed to the differences between the complex microbial community dynamics and the parameterized structure of the model, resulting in comparative inflexibility when simulating systems with significant community changes.

Another relevant aspect may concern the general quality of extended model simulation fits, given the universal set of parameters that was used to generate them. At this point it is important to state that while the focus of the present study was on the implementation and validation of the novel temperature calculation itself, certain assumptions had to be made. On one hand, this involved the selection of the acetoclastic methanogens as the only group with a high sensitivity to variations in temperature, keeping the remaining seven groups unaffected by dynamic temperature changes. While this was a reasonable simplification based on the well-known sensitivity of methanogens to other environmental factors, such as the concentration of inhibitors [52], it can be argued that including dynamic temperature dependence in the growth of the other groups and defining different parameters for them could have improved the simulation results further. At the same time, the choice of a 
universal set of temperature calculation parameters could also be disputed, with the plausible expectation that the set of parameters for the mesophilic S1 and the thermophilic S2 would be different. Once again, the guiding principle during parameter selection was to provide adequate proof that the novel concept is generally applicable to various scenarios, and that the extension describing the real-life correlation with temperature is qualitatively sound. Furthermore, due to the limited amount of available experimental information finding the optimal parameter values for individual groups would have been an unrealistic target, one that was consequently not set.

It is nonetheless clear that selecting specific $\tau_{\mathrm{a}}$ and Shg values for the different cases could have resulted in more accurate simulation results. Some specific examples are shown in Figure 6, where each study case was simulated with the overall best parameters selected from a series of simulations with systematic parameter variations. Due to the high-dimensional parameter space of the novel model system, both global and local parameter estimation methods (Simulated Annealing and Levenberg-Marquardt, respectively) proved to be time-intensive, providing only marginally better estimates than the ones selected manually. Highly accurate simulation results could be achieved with the new model, given the parameter values were taken more meticulously. In these cases, individual VFA concentrations were also simulated and showed good agreement with experimental values (see Supplementary Material A1, Figure S5 and S6).

Even so, for this selection to be generalizable to diverse biological systems, further research is required into the temperature-sensitivity of the methanogenic and other functional groups of the model. Furthermore, as each model group represents an average community of microorganisms with similar functionalities, the effect of temperature on the individual species' growth rate might vary considerably. This and similar aspects necessitate additional investigation into the topic, beyond the scope of the present study. 


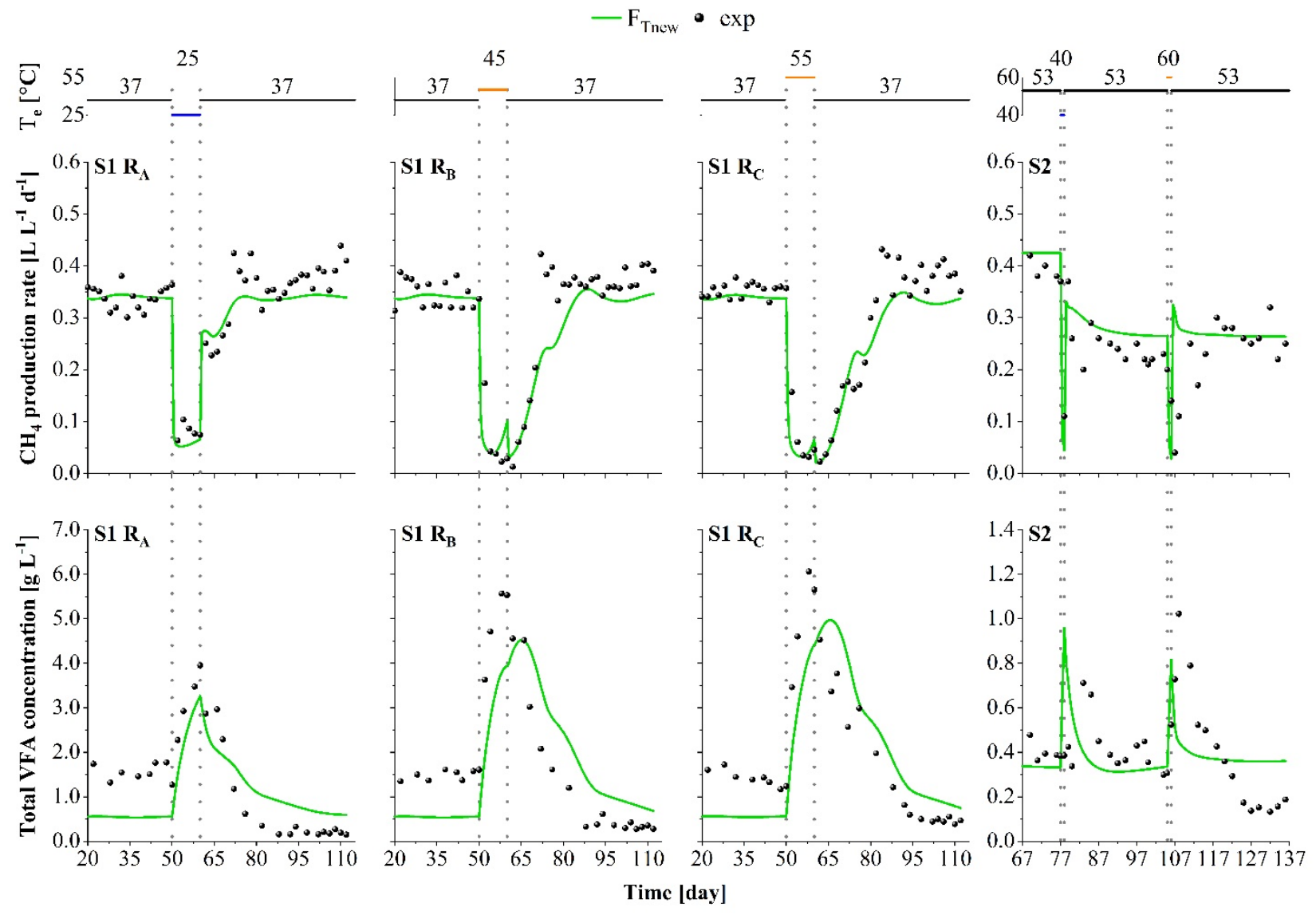

Figure 6: $\mathrm{CH}_{4}$ production rates and total VFA concentration values of $\mathrm{S} 1 \mathrm{R}_{\mathrm{A}}, \mathrm{R}_{\mathrm{B}}$ and $\mathrm{R}_{\mathrm{C}}$ and $\mathrm{S} 2$, taken from the experiment (black dots), and simulated with the newly extended BioModel (green solid lines), using the best parameter values in each case. Parameters for $\mathrm{S} 1 \mathrm{R}_{\mathrm{A}}: \tau_{\mathrm{a}}=30$ days, $\mathrm{Shg}=5{ }^{\circ} \mathrm{C}$; parameters for $\mathrm{S} 1 \mathrm{R}_{\mathrm{B}}: \tau_{\mathrm{a}}=10$ days, $\mathrm{Shg}=2{ }^{\circ} \mathrm{C}$; parameters for $\mathrm{S} 1 \mathrm{R}_{\mathrm{C}}: \tau_{\mathrm{a}}=10$ days, $\mathrm{shg}=4{ }^{\circ} \mathrm{C}$; parameters for S2: $\tau_{\mathrm{a}}=10$ days, Shg $=1{ }^{\circ} \mathrm{C}$. Dotted vertical lines and the scales at the top of the graph indicate the changes in temperature.

\subsection{Energy implications of detailed temperature modeling}

Through the simulation of two experimental AD setups with temperature changes of various duration and magnitude, it was demonstrated that such impactful dynamics can be predicted reliably, using a novel modeling approach. Therefore, it is relevant to assess other, commonly appearing temperature-related phenomena in AD that a dynamic temperature model could potentially forecast, and which have serious implications on project economy. 
Firstly, temperature fluctuations introduced during reactor feeding, due to technical limitations or system malfunctions may be considered, which can unbalance previously steady-state $\mathrm{AD}$, at which point the early containment of unwanted effects is crucial. Depending on the operation conditions, minor temperature variations can lead to a significant reduction in biogas production [14], resulting in the reduced conversion of organic waste material and concurrently - given the phenomenon is experienced in full-scale plants - the accumulation of unrealized revenues.

On the other hand, some processes allow for minor fluctuations in operation temperature [17] or may even benefit from such [53], potentially influencing the economy of AD. In other cases, an increase in process temperature can improve the efficiency of conversion and thereby biogas production [54], although the adaptation of the relevant microbial communities might become an elongated process and eventually lead to unstable performance.

In pilot- and full-scale $\mathrm{AD}$, a permanent shift of operation temperature may lead to larger [55] or smaller [15] gains, in terms of biogas output and the reduction of organic compounds. Under these circumstances, nevertheless, economic feasibility requires that the additional monetary and labor investments in the altered operation are surpassed by increased revenue streams, therefore accurate prognoses on expected costs and benefits are necessary. This is also true for integrated systems, whose profitability depends to a great extent on the optimization of their thermal requirements [56], and where it is of utmost importance to find the ideal temperature point for operation that maximizes process utility.

In extreme cases, when a process is hit so severely by a temperature shift that the partial or complete discard of active biomass becomes necessary, the financial implications become overwhelming. In order to avoid similar situations, process change must be preceded by model simulations, so that the optimal transition steps can be determined and potential threats (such as VFA accumulation or free ammonia inhibition) identified. 
If process temperature dynamics could be understood and handled safely, deliberate temperature changes - in a manner comparable to feed variations - could also become a control option in regulating $\mathrm{AD}$. Among other effects, this would support current efforts in matching energy demand variations (e.g. on a weekly basis) or avoiding the flaring of production surplus, and would allow for a higher penetration of bioenergy in the current production of renewable energy.

\subsection{Further applications}

Although the functionalities of the dynamic temperature effect calculation were presented through BioModel simulations of selected AD experiments, the novel concept established in this work may be implemented in other models as well, an example for which could be the ADM1. Considering that the ADM1 has previously been successfully applied to the simulation of full-scale anaerobic codigestion operations [57,58], and that advanced temperature effect simulation can be relevant for forecasting changes in the microbial community [11] or process variables [15] of AD due to altered temperatures, the new model appears as a promising extension to AD modeling. Moreover, it can potentially be applied to the simulation and optimization of similar and dissimilar anaerobic, or other fermentation processes. These might be related to biofuel and bioenergy production, the thermal stabilization of organic waste, bacterial biomass conversion to value-added chemicals, ethanol fermentation (yeasts) and many other processes applied in the pharmaceutical and cosmetics industries. Similar dynamics may also be relevant when simulating shifts in other types of environmental variables that require timely adaptation. Among others, these could include shifts in $\mathrm{pH}$ or the concentration of inhibitory compounds, where the synthesis of reactive microbial cell components is time-dependent. Such applications would need additional analyses and could provide grounds for interesting future research, furthering the scientific knowledge about the role of temperature in bioprocesses at various scales. 


\section{Conclusion}

The effect of temperature on biochemical processes is a well-known dependence and forms an important element of describing microbial growth. Like many other fields of biotechnology and bioenergy, anaerobic digestion relies heavily on such temperature correlations, and these have been studied extensively under experimental conditions. Until recently, modeling the phenomena was mostly limited to simplified implementations, although there is an increasing demand for effective digital solutions that can reproduce the complexity of contemporary physical applications. In response to these trends, the present study provides a new and dynamic method for simulating the temperatureeffect on the growth of complex microbial communities under anaerobic digestion conditions. Compared to a reference model without the novel implementation, new model simulations achieved significantly higher accuracy when fit to experimental results, both in terms of methane production and total volatile fatty acid concentrations. Despite the need for further optimization with more diverse and microbiologically detailed information, the new model was shown to be an attractive tool for simulating laboratory- and large-scale anaerobic digestion processes with temperature variations. Moreover, it could potentially supplement or augment the simulations of other relevant biochemical processes as well, where dynamic temperature-dependence plays an important role.

\section{Acknowledgements}

The authors would like to thank Energinet for the generous financial support of this study, through the project ForskEL-12465 titled "BioUpgrade - Ex-situ biogas upgrading through biologically mediated $\mathrm{CO}_{2}$ reduction". Additionally, $\mathrm{AK}$ is also grateful to the Otto Mønsted Foundation for the financial support during his external stay.

\section{Competing interests}

The authors declare that they have no competing interests.

\section{Appendix A. Supplementary Material A1}

Appendix B. Supplementary Material A2: Microbial abundance analysis of Study1 and Study2 


\section{References}

[1] Rasi S, Veijanen A, Rintala J. Trace compounds of biogas from different biogas production plants. Energy 2007;32:1375-80. https://doi.org/10.1016/j.energy.2006.10.018.

[2] Alibardi L, Green K, Favaro L, Vale P, Soares A, Cartmell E, Yadira BF. Performance and stability of sewage sludge digestion under $\mathrm{CO}_{2}$ enrichment: A pilot study. Bioresour Technol 2017;245:581-9. https://doi.org/10.1016/j.biortech.2017.08.071.

[3] Bagi Z, Ács N, Böjti T, Kakuk B, Rákhely G, Strang O, Szuhaj M, Wirth R, Kovács KL. Biomethane: The energy storage, platform chemical and greenhouse gas mitigation target. Anaerobe 2017;46:13-22. https://doi.org/10.1016/j.anaerobe.2017.03.001.

[4] Coma M, Martinez-Hernandez E, Abeln F, Raikova S, Donnelly J, Arnot TC, Allen MJ, Hong DD, Chuck CJ. Organic waste as a sustainable feedstock for platform chemicals. Faraday Discuss 2017;202:175-95. https://doi.org/10.1039/C7FD00070G.

[5] Vasco-Correa J, Khanal S, Manandhar A, Shah A. Anaerobic digestion for bioenergy production: Global status, environmental and techno-economic implications, and government policies. Bioresour Technol 2018;247:1015-26. https://doi.org/10.1016/j.biortech.2017.09.004.

[6] Campanaro S, Treu L, Kougias PG, Luo G, Angelidaki I. Metagenomic binning reveals the functional roles of core abundant microorganisms in twelve full-scale biogas plants. Water Res 2018;140:123-34. https://doi.org/10.1016/j.watres.2018.04.043.

[7] Carballa M, Regueiro L, Lema JM. Microbial management of anaerobic digestion: exploiting the microbiome-functionality nexus. Curr Opin Biotechnol 2015;33:103-11. https://doi.org/10.1016/j.copbio.2015.01.008.

[8] Tao Y, Ersahin ME, Ghasimi DSM, Ozgun H, Wang H, Zhang X, Guo M, Yang Y, Stuckey DC, van Lier JB. Biogas productivity of anaerobic digestion process is governed by a core bacterial microbiota. Chem Eng J 2020;380:122425. https://doi.org/10.1016/j.cej.2019.122425.

[9] Alster CJ, Weller ZD, von Fischer JC. A meta-analysis of temperature sensitivity as a microbial trait. Glob Change Biol 2018;24:4211-24. https://doi.org/10.1111/gcb.14342.

[10] Levén L, Eriksson ARB, Schnürer A. Effect of process temperature on bacterial and archaeal communities in two methanogenic bioreactors treating organic household waste: Temperature effects on microbial communities in bioreactors. FEMS Microbiol Ecol 2007;59:683-93. https://doi.org/10.1111/j.1574-6941.2006.00263.x.

[11] Lin Q, He G, Rui J, Fang X, Tao Y, Li J, Li X. Microorganism-regulated mechanisms of temperature effects on the performance of anaerobic digestion. Microb Cell Factories 2016;15:96. https://doi.org/10.1186/s12934-016-0491-x.

[12] Shaw GT-W, Weng C-Y, Chen C-Y, Weng FC-H, Wang D. A systematic approach re-analyzing the effects of temperature disturbance on the microbial community of mesophilic anaerobic digestion. Sci Rep 2019;9:6560. https://doi.org/10.1038/s41598-019-42987-0.

[13] Zhu X, Kougias PG, Treu L, Campanaro S, Angelidaki I. Microbial community changes in methanogenic granules during the transition from mesophilic to thermophilic conditions. Appl Microbiol Biotechnol 2017;101:1313-22. https://doi.org/10.1007/s00253-016-8028-0.

[14] Navickas K, Venslauskas K, Petrauskas A, Zuperka V. INFLUENCE OF TEMPERATURE VARIATION ON BIOGAS YIELD FROM INDUSTRIAL. Proc Eng RURAL Dev 2013;12:405-10.

[15] Tukacs-Hájos A, Pap B, Maróti G, Szendefy J, Szabó P, Rétfalvi T. Monitoring of thermophilic adaptation of mesophilic anaerobe fermentation of sugar beet pressed pulp. Bioresour Technol 2014;166:288-94. https://doi.org/10.1016/j.biortech.2014.05.059.

[16] Gaby JC, Zamanzadeh M, Horn SJ. The effect of temperature and retention time on methane production and microbial community composition in staged anaerobic digesters fed with food waste. Biotechnol Biofuels 2017;10:302. https://doi.org/10.1186/s13068-017-0989-4. 
[17] El-Mashad HM, Zeeman G, van Loon WKP, Bot GPA, Lettinga G. Effect of temperature and temperature fluctuation on thermophilic anaerobic digestion of cattle manure. Bioresour Technol 2004;95:191-201. https://doi.org/10.1016/j.biortech.2003.07.013.

[18] Ustundag A, Cevikcan E. Industry 4.0: Managing The Digital Transformation. Cham: Springer International Publishing; 2018. https://doi.org/10.1007/978-3-319-57870-5.

[19] Tomei MC, Braguglia CM, Cento G, Mininni G. Modeling of Anaerobic Digestion of Sludge. Crit Rev Environ Sci Technol 2009;39:1003-51. https://doi.org/10.1080/10643380801977818.

[20] Xie S, Hai FI, Zhan X, Guo W, Ngo HH, Price WE, Nghiem LD. Anaerobic co-digestion: A critical review of mathematical modelling for performance optimization. Bioresour Technol 2016;222:498-512. https://doi.org/10.1016/j.biortech.2016.10.015.

[21] Angelidaki I, Ellegaard L, Ahring BK. A mathematical model for dynamic simulation of anaerobic digestion of complex substrates: Focusing on ammonia inhibition. Biotechnol Bioeng 1993;42:159-66. https://doi.org/10.1002/bit.260420203.

[22] Angelidaki I, Ellegaard L, Ahring BK. A comprehensive model of anaerobic bioconversion of complex substrates to biogas. Biotechnol Bioeng 1999;63:363-72.

[23] Batstone DJ, International Water Association, editors. Anaerobic digestion model no. 1: (ADM1). London: IWA Publ; 2002.

[24] Bergland WH, Dinamarca C, Bakke R. Temperature Effects in Anaerobic Digestion Modeling, 2015, p. 261-9. https://doi.org/10.3384/ecp15119261.

[25] Westerholm M, Isaksson S, Karlsson Lindsjö O, Schnürer A. Microbial community adaptability to altered temperature conditions determines the potential for process optimisation in biogas production. Appl Energy 2018;226:838-48. https://doi.org/10.1016/j.apenergy.2018.06.045.

[26] Abendroth C, Hahnke S, Simeonov C, Klocke M, Casani-Miravalls S, Ramm P, Bürger C, Luschnig O, Porcar M. Microbial communities involved in biogas production exhibit high resilience to heat shocks. Bioresour Technol 2018;249:1074-9. https://doi.org/10.1016/j.biortech.2017.10.093.

[27] Boušková A, Dohányos M, Schmidt JE, Angelidaki I. Strategies for changing temperature from mesophilic to thermophilic conditions in anaerobic CSTR reactors treating sewage sludge. Water Res 2005;39:1481-8. https://doi.org/10.1016/j.watres.2004.12.042.

[28] Nguyen D, Gadhamshetty V, Nitayavardhana S, Khanal SK. Automatic process control in anaerobic digestion technology: A critical review. Bioresour Technol 2015;193:513-22. https://doi.org/10.1016/j.biortech.2015.06.080.

[29] Pavlostathis SG, Giraldo-Gomez E. Kinetics of anaerobic treatment: A critical review. Crit Rev Environ Control 1991;21:411-90. https://doi.org/10.1080/10643389109388424.

[30] Smelt JPPM, Brul S. Thermal Inactivation of Microorganisms. Crit Rev Food Sci Nutr 2014;54:1371-85. https://doi.org/10.1080/10408398.2011.637645.

[31] Kythreotou N, Florides G, Tassou SA. A review of simple to scientific models for anaerobic digestion. Renew Energy 2014;71:701-14. https://doi.org/10.1016/j.renene.2014.05.055.

[32] Rosso L, Lobry JR, Flandrois JP. An Unexpected Correlation between Cardinal Temperatures of Microbial Growth Highlighted by a New Model. J Theor Biol 1993;162:447-63. https://doi.org/10.1006/jtbi.1993.1099.

[33] Huang L, Hwang A, Phillips J. Effect of Temperature on Microbial Growth Rate-Mathematical Analysis: The Arrhenius and Eyring-Polanyi Connections. J Food Sci 2011;76:E553-60. https://doi.org/10.1111/j.1750-3841.2011.02377.x.

[34] Kovalovszki A, Alvarado-Morales M, Fotidis IA, Angelidaki I. A systematic methodology to extend the applicability of a bioconversion model for the simulation of various co-digestion scenarios. Bioresour Technol 2017;235:157-66. https://doi.org/10.1016/j.biortech.2017.03.101.

[35] MATLAB. Natick, Massachusetts: The MathWorks, Inc.; 2018.

[36] Prakash D, Chauhan SS, Ferry JG. Life on the thermodynamic edge: Respiratory growth of an acetotrophic methanogen. Sci Adv 2019;5:eaaw9059. https://doi.org/10.1126/sciadv.aaw9059. 
[37] Luo G, De Francisci D, Kougias PG, Laura T, Zhu X, Angelidaki I. New steady-state microbial community compositions and process performances in biogas reactors induced by temperature disturbances. Biotechnol Biofuels 2015;8:3. https://doi.org/10.1186/s13068-014-0182-y.

[38] Sun H, Kovalovszki A, Tsapekos P, Alvarado-Morales M, Rudatis A, Wu S, Dong R, Kougias PG, Angelidaki I. Co-digestion of Laminaria digitata with cattle manure: A unimodel simulation study of both batch and continuous experiments. Bioresour Technol 2019;276:3618. https://doi.org/10.1016/j.biortech.2018.12.110.

[39] Søndergaard MM, Fotidis IA, Kovalovszki A, Angelidaki I. Anaerobic Co-digestion of Agricultural Byproducts with Manure for Enhanced Biogas Production. Energy Fuels 2015;29:8088-94. https://doi.org/10.1021/acs.energyfuels.5b02373.

[40] Meyer F, Paarmann D, D’Souza M, Olson R, Glass E, Kubal M, Paczian T, Rodriguez A, Stevens R, Wilke A, Wilkening J, Edwards R. The metagenomics RAST server - a public resource for the automatic phylogenetic and functional analysis of metagenomes. BMC Bioinformatics 2008;9:386. https://doi.org/10.1186/1471-2105-9-386.

[41] Treu L, Kougias PG, de Diego-Díaz B, Campanaro S, Bassani I, Fernández-Rodríguez J, Angelidaki I. Two-year microbial adaptation during hydrogen-mediated biogas upgrading process in a serial reactor configuration. Bioresour Technol 2018;264:140-7. https://doi.org/10.1016/j.biortech.2018.05.070.

[42] Caporaso JG, Lauber CL, Walters WA, Berg-Lyons D, Lozupone CA, Turnbaugh PJ, Fierer N, Knight R. Global patterns of 16S rRNA diversity at a depth of millions of sequences per sample. Proc Natl Acad Sci 2011;108:4516-22. https://doi.org/10.1073/pnas.1000080107.

[43] Campanaro S, Treu L, Kougias PG, Zhu X, Angelidaki I. Taxonomy of anaerobic digestion microbiome reveals biases associated with the applied high throughput sequencing strategies. Sci Rep 2018;8:1926. https://doi.org/10.1038/s41598-018-20414-0.

[44] Yarza P, Yilmaz P, Pruesse E, Glöckner FO, Ludwig W, Schleifer K-H, Whitman WB, Euzéby J, Amann R, Rosselló-Móra R. Uniting the classification of cultured and uncultured bacteria and archaea using 16S rRNA gene sequences. Nat Rev Microbiol 2014;12:635-45. https://doi.org/10.1038/nrmicro3330.

[45] Saeed AI, Bhagabati NK, Braisted JC, Liang W, Sharov V, Howe EA, Li J, Thiagarajan M, White JA, Quackenbush J. [9] TM4 Microarray Software Suite. Methods Enzymol., vol. 411, Elsevier; 2006, p. 134-93. https://doi.org/10.1016/S0076-6879(06)11009-5.

[46] Parks DH, Beiko RG. Identifying biologically relevant differences between metagenomic communities. Bioinformatics 2010;26:715-21. https:/doi.org/10.1093/bioinformatics/btq041.

[47] Torondel B, Ensink JHJ, Gundogdu O, Ijaz UZ, Parkhill J, Abdelahi F, Nguyen V-A, Sudgen S, Gibson W, Walker AW, Quince C. Assessment of the influence of intrinsic environmental and geographical factors on the bacterial ecology of pit latrines: Bacterial ecology of pit latrines. Microb Biotechnol 2016;9:209-23. https://doi.org/10.1111/1751-7915.12334.

[48] Montgomery DC, Runger GC. Applied statistics and probability for engineers. 3rd ed. New York: Wiley; 2003.

[49] OriginPro. Northampton, MA, USA: OriginLab Corporation; 2015.

[50] Lambie SC, Kelly WJ, Leahy SC, Li D, Reilly K, McAllister TA, Valle ER, Attwood GT, Altermann E. The complete genome sequence of the rumen methanogen Methanosarcina barkeri CM1. Stand Genomic Sci 2015;10:57. https://doi.org/10.1186/s40793-015-0038-5.

[51] Gao WJ, Leung KT, Qin WS, Liao BQ. Effects of temperature and temperature shock on the performance and microbial community structure of a submerged anaerobic membrane bioreactor. Bioresour Technol 2011;102:8733-40. https://doi.org/10.1016/j.biortech.2011.07.095.

[52] Tian H, Fotidis IA, Kissas K, Angelidaki I. Effect of different ammonia sources on aceticlastic and hydrogenotrophic methanogens. Bioresour Technol 2018;250:390-7. https://doi.org/10.1016/j.biortech.2017.11.081. 
[53] Nielsen M, Holst-Fischer C, Malmgren-Hansen B, Bjerg-Nielsen M, Kragelund C, Møller HB, Ottosen LDM. Small temperature differences can improve the performance of mesophilic sludge-based digesters. Biotechnol Lett 2017;39:1689-98. https://doi.org/10.1007/s10529-0172418-y.

[54] Tassew FA, Bergland WH, Dinamarca C, Bakke R. Influences of Temperature and Substrate Particle Content on Granular Sludge Bed Anaerobic Digestion. Appl Sci 2019;10:136. https://doi.org/10.3390/app10010136.

[55] Cavinato C, Bolzonella D, Pavan P, Fatone F, Cecchi F. Mesophilic and thermophilic anaerobic co-digestion of waste activated sludge and source sorted biowaste in pilot- and full-scale reactors. Renew Energy 2013;55:260-5. https://doi.org/10.1016/j.renene.2012.12.044.

[56] Baccioli A, Ferrari L, Guiller R, Yousfi O, Vizza F, Desideri U. Feasibility Analysis of BioMethane Production in a Biogas Plant: A Case Study. Energies 2019;12:473. https://doi.org/10.3390/en12030473.

[57] Nordlander E, Thorin E, Yan J. Investigating the possibility of applying an ADM1 based model to a full-scale co-digestion plant. Biochemical Engineering Journal 2017;120:73-83. https://doi.org/10.1016/j.bej.2016.12.014.

[58] Satpathy P, Biernacki P, Cypionka H, Steinigeweg S. Modelling anaerobic digestion in an industrial biogas digester: Application of lactate-including ADM1 model (Part II). Journal of Environmental Science and Health, Part A 2016;51:1226-32. https://doi.org/10.1080/10934529.2016.1212559. 